\title{
Caring for Older Adults in Disasters: A Special Collection of Papers for a Special Population
}

\author{
Kelly Gulley, MPH; Kandra Strauss-Riggs, MPH; Craig Goolsby, MD, MEd
}

$\mathrm{T}$

he increasing number of disasters and an aging population makes the care of older adults (defined as persons aged 65 years and older $^{1}$ ) in disasters worthy of special consideration. Between 2012 and 2050, the United States will experience substantial growth in its older population. ${ }^{2}$ Older adults are anticipated to represent $21.7 \%$ of the total population in the United States by $2040 .^{2}$ Older adults suffer higher morbidity from disasters, and several studies show that disasters impact older adults more significantly than other segments of the population. ${ }^{3-12}$ This combination of a growing population that is disproportionately affected by disasters makes the scholarship and science of caring for older adults in these settings more important than ever.

To address this need for better scholarship, the National Center for Disaster Medicine and Public Health (NCDMPH), in collaboration with the journal Disaster Medicine and Public Health Preparedness, presents a special collection of papers on caring for older adults before, during, and after disasters. This special collection is the first set of papers of its kind focused on the care of older adults in catastrophes. These papers aim to bring together the most relevant research, practice, and educational initiatives while building the evidence base on the care of older adults in disasters.

Authors representing a wide variety of disciplines submitted manuscripts in response to a call for papers. These articles included a mix of original research, brief reports, responder tools, letters to the editor, and commentaries. Submissions address issues related to disaster preparedness, response, recovery, and resilience. Manuscripts submitted for this special collection underwent peer review, per journal policy, prior to publication.

This special collection is a significant step toward enhancing disaster health science and helps NCDMPH advance its mission of service as the nation's academic center of excellence leading domestic and international disaster health education and research efforts. In collaboration with federal, state, local, academic, and organizational partners, the NCDMPH creates and translates science and education to improve readiness. NCDMPH is housed at the Uniformed Services University of the Health Sciences. NCDMPH looks forward to increased engagement, intellectual exchange, and disaster readiness for our communities resulting from publication of this special collection.

This special collection of papers was edited by a series of guests including the following:

- Kandra Strauss-Riggs, MPH, Operations Director, Henry M. Jackson Foundation for the Advancement of Military Medicine.

- Kelly Gulley, MPH, Project Coordinator, Henry M. Jackson Foundation for the Advancement of Military Medicine.

- Brian A. Altman, PhD, Education Director, Henry M. Jackson Foundation for the Advancement of Military Medicine.

- Kenneth W. Schor, DO, MPH, FAAFP, Director for Preventive Medicine and Public Health, The Edward Via College of Osteopathic Medicine, Previous Acting Director, NCDMPH, Uniformed Services University of the Health Sciences.

- Melen G. R. McBride, PhD, MSN, MEd, RN, FGSA, Associate Director, Emerita, Stanford Geriatric Education Center, Stanford University, School of Medicine.

\begin{abstract}
About the Authors
Henry M. Jackson Foundation for the Advancement of Military Medicine, Inc, and National Center for Disaster Medicine and Public Health, Rockville, Maryland (Ms Gulley, Ms Strauss-Riggs), and Department of Military $\mathcal{E}$ Emergency Medicine, Uniformed Services University of the Health Sciences, Bethesda, Maryland, and National Center for Disaster Medicine and Public Health, Rockville, Maryland (Dr Goolsby).

Correspondence and reprint requests to Kelly Gulley, MPH, National Center for Disaster Medicine and Public Health (NCDMPH), Uniformed Services University of the Health Sciences (USU), 11300 Rockville Pike, Ste 1000, Rockville, MD 20852 (e-mail: Kelly.gulley. ctr@usuhs.edu).
\end{abstract}

\section{Disclaimer}

The Henry M. Jackson Foundation for the Advancement of Military Medicine, Inc, supports the National Center for Disaster Medicine and Public Health through a grant sponsored by the Uniformed Services University of the Health Sciences. The views expressed here are those of the authors and do not reflect the official policy or position of the Uniformed Services University of the Health Sciences, the US Department of Defense, or the US government. 


\section{REFERENCES}

1. Barclay L. Guidelines for psychological practice with older adults. Am Psychol. 2004;59(4):236-260. http://dx.doi.org/10.1037/0003-066X.59.4.236.

2. Ortman JM, Velkoff VA, Hogan H. An Aging Nation: The Older Population in the United States. Population Estimates and Projections. Current Population Reports. https://www.census.gov/prod/2014pubs/p251140.pdf. Published May 2014. Accessed January 13, 2017.

3. Administration on Aging (AoA). Aging Statistics. Administration for Community Living website. http://www.aoa.acl.gov/Aging_Statistics/ index.aspx. Accessed December 28, 2015.

4. Jenkins JL, Levy M, Rutkow L, Spira A. Variables associated with effects on morbidity in older adults following disasters. PLoS Currents. 2014;6: ecurrents.dis.0fe970aa16d51cde6a962b7a732e494a. doi: http://dx.doi. org/10.1371/currents.dis.Ofe970aa16d51cde6a962b7a732e494a.

5. Psychological and emotional effects of the September 11 attacks on the World Trade Center-Connecticut, New Jersey, and New York, 2001. MMWR Morb Mortal Wkly Rep. 2002;51(35):784-786.

6. Rapid assessment of the needs and health status of older adults after Hurricane Charley-Charlotte, DeSoto, and Hardee Counties, Florida, August 27-31, 2004. MMWR Morb Mortal Wkly Rep. 2004;53(36):837-840.
7. Assessment of health-related needs after Hurricanes Katrina and Rita-Orleans and Jefferson Parishes, New Orleans area, Louisiana, October 17-22, 2005. MMWR Morb Mortal Wkly Rep. 2006;55(2): 38-41.

8. Evans J. Mapping the vulnerability of older persons to disasters. Int J Older People Nurs. 2010;5(1):63-70. http://dx.doi.org/10.1111/j.17483743.2009.00205.x.

9. Fernandez LS, Byard D, Lin CC, et al. Frail elderly as disaster victims: emergency management strategies. Prehosp Disaster Med. 2002; 17(2):67-74. http://dx.doi.org/10.1017/S1049023X00000200.

10. Gibson MJ. We Can Do Better: Lessons Learned for Protecting Older Persons in Disasters. Washington, DC: American Association of Retired Persons; 2006. https://assets.aarp.org/rgcenter/il/better.pdf. Accessed January 4, 2014.

11. Somes J, Stephens Donatelli N. Disaster planning considerations involving the geriatric patient: part I. J Emerg Nurs. 2012; 38(5):479-481. PubMed PMID:22819373.

12. Trust for America's Health. Ready or not? 2006. Protecting the Public's Health from Disease, Disasters, and Bioterrorism. http://healthya mericans.org/reports/bioterror06/. Published December 2006. Retrieved December 10, 2013. 